\title{
INVESTIGACIÓN
}

Recibido: 03/09/2019 --- Aceptado: 13/02/2020 --- Publicado: 15/12/2020

\section{APROXIMACIÓN AL FRAMING EN MEDIOS TRADICIONALES Y EN NATIVOS DIGITALES. EL CASO DEL IMPUESTO A LAS HIPOTECAS EN ESPAÑA}

\author{
An approach to framing in traditional media and digital natives. The case of the \\ mortgage tax in Spain
}

Leticia Quintana Pujalte: Universidad de Málaga. España. 1.quintanapujallte@uma.es

Investigación parcialmente financiada por la Asociación Universitaria Iberoamericana de Posgrado (AUIP)

\section{RESUMEN}

Entre octubre y noviembre de 2018 las deliberaciones sobre quién debe pagar los impuestos de las hipotecas -si el cliente o la Banca- tuvieron una repercusión económica, política y por supuesto, mediática en España. Desde un enfoque marcado por el framing y con el objetivo de identificar diferencias y similitudes, se interpretan los encuadres que ofrecieron sobre este tema los medios tradicionales y los nativos digitales del país ibérico. La perspectiva es innovadora porque se comparan los encuadres en estos medios con orígenes diferenciados. A partir de una metodología de análisis de contenido mixta se analizaron piezas informativas correspondientes a los medios de referencia en España. El País, El Mundo, Elconfidencial.com y Eldiario.es. Entre los resultados más relevantes está la privilegiada presencia de la Banca en los encuadres de los medios, y de las fuentes político-institucionales. Se concluyó también que el framing varía si se realiza desde medios tradicionales o desde medios nativos digitales, por el particular uso de las fuentes de información y los valores culturales a los que éstas apelan. La hegemonía del discurso de la Banca propicia una opinión pública que conoce de modo preferencial los intereses de estos grupos privados.

PALABRAS CLAVE: Medios de comunicación social; medios digitales; Teoría del framing; encuadre mediático; análisis de contenido

\section{ABSTRACT}

Between October and November 2018 the deliberations on who should pay the mortgage taxes - whether the client or the Bank - had an economic, political and, of 
course, media impact in Spain. From an approach marked by framing and with the objective of identifying differences and similarities, the frames offered by the traditional media and digital natives of the Iberian country are interpreted on this issue. The perspective is innovative because the frames in these media are compared with differentiated origins. Based on a mixed content analysis methodology, information pieces corresponding to the reference media in Spain were analyzed. El País, El Mundo, Elconfidencial.com and Eldiario.es. Among the most relevant results is the privileged presence of the Bank in the frameworks of the media, and of the political-institutional sources. It was also concluded that framing varies if it is done from traditional media or from digital native media, due to the particular use of information sources and the cultural values to which they appeal. The hegemony of the Bank's discourse fosters a public opinion that preferentially knows the interests of these private groups.

KEY WORDS: Traditional media, digital media, framing theory, media framing, content analysis.

\section{APROXIMAÇÃO AO FRAMING EM MEIOS TRADICIONAIS E EM NATIVOS DIGITAIS. O CASO DA TAXA DAS HIPOTECAS NA ESPANHA}

\section{RESUMO}

Entre outubro e novembro de 2018 as deliberações sobre quem deve pagar as taxas das hipotecas -se o cliente ou o Banco- tiveram uma repercussão econômica, política e claro, mediática na Espanha. Desde um enfoque marcado pelo framing e com o objetivo de identificar diferenças e semelhanças, se interpretam as molduras que ofereceram sobre o tema os meios tradicionais e os nativos digitais do país ibérico. A perspectiva é inovadora porque se comparam as configurações destes meios com origens diferenciados. A partir de uma metodologia de análise de conteúdo misturado se analisaram peças informativas correspondentes aos meios de referência na Espanha. El País, El Mundo, Elconfidencial.com e Eldiario.es. Entre os resultados mais relevantes está a privilegiada presença da Banca nos moldes dos meios, e das fontes político-institucionais. Se concluiu também que o framing varia se for realizado desde meios tradicionais ou desde meios nativos digitais, pelo particular uso das fontes de informação e os valores culturais que estas procuram. A hegemonia do discurso da Banca propício uma opinião pública que conhece de modo preferencial os interesses destes grupos privados.

PALAVRAS CHAVE: Meios de comunicação social; meios digitais; Teoria do framing; enquadramento midiático; análise de conteúdo 
Aproximación al Framing en medios tradicionales y en nativos digitales. El caso del impuesto a las hipotecas en España

Como citar el artículo:

Quintana Pujalte, L. (2020). Aproximación al Framing en medios tradicionales y en nativos digitales. El caso del impuesto a las hipotecas en España. [An approach to framing in traditional media and digital natives. The case of the mortgage tax in Spain]. Vivat Academia. Revista de Comunicación, 153, 1-28. doi: https://doi.org/10.15178/va.2020.153.1-28 Recuperado de:

http:// www.vivatacademia.net/index.php/vivat/article/view/1204

\section{INTRODUCCIÓN}

El presente estudio se propone investigar el modo en que los medios encuadran el tratamiento de un tema que tiene especial relación con grupos de presión en la sociedad (Easton, 1965; Dion, 1967; Andersen y Eliassen, 1991; Castillo-Esparcia, 2011; Castillo-Esparcia, Smolak y Fernández, 2017) e identificar posibles diferencias de encuadre que ofrecen los medios tradicionales y los nativos digitales con altos índices de audiencia en España.

Para hacerlo, se seleccionó como caso de estudio el tratamiento mediático que se realizó sobre el fallo e impacto del Tribunal Supremo de España, publicado el 16 de octubre de 2018, en el cual se sentenció que es la Banca y no el usuario quien debía afrontar el pago de los impuestos por la conformación de una hipoteca.

El tema tuvo repercusiones económicas y políticas, y se mantuvo en la agenda mediática durante veinticinco días: desde la Sentencia, que tuvo impacto económico y financiero para los bancos que cotizan en Bolsa con pérdidas significativas en el valor de sus acciones; luego la convocatoria a las deliberaciones del Poder Judicial que llevaron a un Pleno que derivó en que se decida volver a la jurisprudencia anterior en la que era el cliente quien debía pagar el impuesto, y la final respuesta de la Administración del Presidente Pedro Sánchez que dictó el Real Decreto Ley del 8 de noviembre, a partir del cual se establece nuevamente que es la Banca la responsable de pagarlo.

Se entiende que es un ejemplo que reúne varias características de lo noticiable (Warren, 1979), ya que afecta a un gran número de personas debido a la cultura de la compra de viviendas en España; implica a actores políticos poderosos entre los que se destacan la Banca, y los representantes de los poderes Ejecutivo y Judicial; y tiene altas implicancias económicas, tanto para los bancos que cotizan en Bolsa (hubo registro de caídas en el mercado de valores) como para la ciudadanía en general.

\subsection{Marco teórico}

El crecimiento de los estudios desde el framing se evidencia en investigaciones realizadas sobre el rol que juega el encuadre, por ejemplo, en la prensa gráfica (Berrocal, Redondo y Torres, 2015; Igartúa, Muñiz y Cheng, 2005; Rodríguez-Pérez, 2017, entre otros), en formatos periodísticos televisivos (Mercado-Sáez, y Monedero 
Quintana Pujalte, L.

Aproximación al Framing en medios tradicionales y en nativos digitales. El caso del impuesto a las hipotecas en España

Morales, 2017) y en medios digitales (Rúas-Araújo, Mazaira y Rodríguez-Vázquez, 2018; Tirado-Pascual, 2016; Sánchez-Castillo, Fenoll y Peris-Blanes, 2016). Es evidente que esta teoría se ha ido consolidando en tanto marco analítico y metodológico en los estudios de comunicación, tal como lo expresan Piñeiro-Naval y Mangana (2019).

Las herramientas que propone el framing pretenden develar aquellos aspectos que se vuelven prominentes en cierto asunto público, y cómo lo hacen más noticiable e incluso memorable para las audiencias.

Para Entman -uno de sus máximos exponentes- el framing se traduce en el proceso de elección de unos pocos elementos de una realidad percibida y ensamblaje de una narración que destaque las conexiones entre ellos y el fomento de una interpretación particular [...] Los encuadres introducen o elevan el énfasis o la aparente importancia de ciertas ideas, activando esquemas que inducen a las audiencias a pensar, sentir y decidir de una forma particular. (Entman, 2007, p. 164).

Cabe destacar que para el autor no existe una influencia directa entre los encuadres mediáticos y los encuadres de los individuos en sociedad, sino que son parte del esquema de conocimiento compartido entre el emisor y el receptor, coincidentes o no entre sí, y en la cultura en la que aparecen los mensajes en donde además consolidan y acumulan los frames (Entman, 1993). La relevancia de esos lugares de interpretación en común propician cierta construcción de la realidad, porque "ayuda a compartir las perspectivas mediante las que la gente ve el mundo". (Hallahan, 1999, p. 207).

La teoría del framing tiene como bases epistemológicas la sociología interpretativa, alimentada por el interaccionismo de la Escuela de Chicago, la fenomenología de Shutz, Berger y Luckmahn, y la Etnometodología de Garfinkel (Sádaba-Garraza, 2001). Para Goffman (2006) la organización de la realidad que realizan los frames no se da sólo a nivel mental, sino también de modo pronunciado en la sociedad.

Desde esta base, Tuchman (1983) sugiere a partir del constructivismo social, la inclusión de los frames en el estudio de la construcción informativa. En el marco de los estudios de comunicación, esta teoría se preocupa por conocer de qué modo se construye el significado en una sociedad (Hänggli y Kriesi, 2010) a través de principios organizativos compartidos y persistentes a lo largo del tiempo (Reese, 2001).

Semetko y Valkenburg (2000) y De Vreese (2005), consideran la existencia de dos posibles aproximaciones para el análisis de los encuadres mediáticos: la inductiva y la deductiva. En el primer caso, los encuadres "emergen del material durante el curso del análisis" (De Vreese, 2005, p. 53). En el caso de la aproximación deductiva, hay encuadres preconcebidos que se pretende encontrar en las informaciones publicadas. Neuman, Just y Crigler (1992) hablan de cuatro frames generales: de conflicto, de interés humano, de consecuencias económicas y de juicio moral. 
Por su parte, D'Angelo (2002) señalaba que:

El núcleo de la línea de investigación sobre los encuadres noticiosos se refleja en cuatro objetivos empíricos que los estudios han perseguido de diferentes formas. Estos objetivos son: (a) identificar las unidades temáticas llamadas encuadres; (b) investigar las condiciones previas que producen los encuadres; (c) examinar cómo los encuadres noticiosos activan, e interactúan con, el conocimiento principal de un individuo que afecta a sus interpretaciones, solicitudes de información, tomas de decisiones y evaluaciones; y (d) examinar cómo los encuadres noticiosos modelan procesos sociales como la opinión pública y los debates sobre temas políticos (D’Angelo, 2002, p. 873)

El estudio que aquí se presenta realiza una aproximación de tipo inductiva, ya que a partir del universo de análisis se busca identificar patrones de interpretación que ofrecen los medios seleccionados sobre el acontecimiento estudiado. Siguiendo a Sádaba-Garraza (2001, p. 168) se parte de la premisa de que "son las relaciones de poder las que determinan los frames de las noticias".

El conocimiento que se produce socialmente a partir del encuadre mediático es valioso, especialmente desde el enfoque que busca conocer y estudiar el modo en que comprendemos el mundo político desde los medios de comunicación.

\subsection{Sobre las fuentes de información}

Para la teoría de framing "el papel de los medios resulta decisivo en cuanto que, en el intento de explicar los acontecimientos a la audiencia, están ya definiendo las nuevas realidades" (Sádaba, Rodríguez y La Porte, 2008, p. 15).

El rol de los encuadres cumple "al menos dos de las siguientes funciones: define efectos o condiciones problemáticas; identifica causas; transmite un juicio moral sobre el tema o problema tratado; y respalda mejoras a la situación problemática" (Entman, 2003, p. 417).

Siguiendo a Sádaba et. al (2008, p. 22), es destacable identificar en el análisis tres elementos relevantes en los encuadres que ofrecen los medios: las resonancias culturales, las resonancias mediáticas y las resonancias personales. Sobre la primera, los autores indican que "un frame es más efectivo en la medida en la que apela a valores compartidos, lugares comunes para una sociedad". En cuanto a las resonancias mediáticas, esta categoría hace referencia al modo de producción periodística, ya que "un frame es más replicable en la medida en que 'entra' fácil en los medios porque cumple con ciertos criterios de noticiabilidad". Por último, estiman que habría que considerar la "inclusión de los frames de la experiencia personal o colectiva de distintos acontecimientos", identificados como las resonancias personales. 

a las hipotecas en España

Una pieza clave en esta teoría se refiere al uso de las fuentes informativas presentes en las noticias (Entman, 2003) y de qué modo los medios y los periodistas pueden colaborar en la construcción de ciertos encuadres. Como indican Sádaba y Rodríguez-Virgili "el papel de los medios que filtran la realidad al seleccionar contenidos o presentarlos de modo determinado, así como la concurrencia de actores sociales e instituciones son factores que deben considerarse para precisar quién está influyendo realmente en la agenda pública". (Sadaba y Rodríguez-Virgili, 2006, p. 213). Su importancia radica en comprender que el acceso privilegiado de ciertos actores políticos refuerza su status y consolida su influencia (Gans, 1980).

De modo que es importante detectar el poder de comunicación de los actores que se constituyen como fuentes informativas en la construcción de las noticias, y es relevante identificar las resonancias culturales, mediáticas y personales del tema que resulta de interés para conocer los encuadres que emergen de las piezas informativas a partir del tratamiento que se realiza desde los medios.

\subsection{Escenario digital}

El papel fundamental de los medios tradicionales en la formación de la opinión pública y el establecimiento de temas de debate es ya indiscutible (McCombs, 2004). Sin embargo, el surgimiento de Internet y de los medios nativos digitales significó una necesidad de revisión y de actualización de los marcos teóricos y metodológicos de la comunicación política.

Según el Resumen General de Medios de España Internet ostenta una creciente audiencia, que puede ser comparada solo con los índices que logra la televisión, pero que a diferencia de esta última, muestra permanentes índices en alza en las lecturas interanuales (RSG, 2018).

Los usuarios dividen casi el total de su navegación entre redes sociales -entre las que se destaca su presencia en Youtube, Facebook y Twitter- y medios informativos con presencia en internet (RGM, 2018, p. 18).

Este escenario es un espacio que se suma al que ofrecían los medios tradicionales, como la prensa gráfica, para poder poner en circulación otros enfoques en los discursos sociales, y propiciar un debate público desde una ciudadanía que tiene mayor acceso a información más diversa (Happer y Philo, 2013).

En esta línea, distintos autores ponen el acento en la distribución del poder que significan estas nuevas herramientas de comunicación (Benkler, 2015) mientras que otros defienden una postura menos optimista en cuanto al verdadero poder movilizador que tienen los nuevos medios (Morozov, 2013).

Los nativos digitales significan un tema de interés desde su aparición en el sistema mediático ya que "estos nuevos medios responden a modelos económicos alternativos, sin un gran grupo empresarial que condicione su tratamiento 
Quintana Pujalte, L.

Aproximación al Framing en medios tradicionales y en nativos digitales. El caso del impuesto a las hipotecas en España

informativo. Muchos de ellos están configurados en modo cooperativista o mediante la aportación de socios que proporcionan pequeñas cantidades de dinero para garantizar la independencia económica" (Tirado-Pascual, 2016, p. 261).

El potencial de comunicación sin ataduras que ofrecen los medios digitales debido a las características mencionadas es interesante ya que "la imagen de las instituciones políticas se forma y depende de los medios de comunicación" (Tirado-Pascual, 2016, p. 265).

Asimismo, el tratamiento con las fuentes informativas es crucial para la construcción del discurso mediático. Sin importar si son o no nativos digitales, la variedad, credibilidad y transparencia de las fuentes fortalece la calidad periodística de los medios. Por el contrario, si en las informaciones aparece un alto porcentaje de fuentes sin identificar, esto se relaciona con poca calidad informativa (CaseroRipollés y López-Rabadán, 2013).

La co-presencia de medios tradicionales y de nativos digitales genera un sistema mediático híbrido (Jenkins, 2008; Chadwick, 2013) que construye un "complejo sistema basado en la adaptación, interdependencia y difusión del poder" (RúasAraújo et al. 2018).

Este contexto invita a preguntar si existen diferencias o similitudes entre la presencia o ausencia de discursos sociales y de actores políticos en el tratamiento que realizan los medios de los temas que publican, y el modo en que se encuadran los acontecimientos de interés público con implicancias económicas y políticas.

Por ello, se busca en interpretar la influencia que tienen los encuadres predominantes desde los medios hacia la opinión pública, al entender que los frames tienen "la habilidad para conectar los encuadres con aspectos emocionales que escapan del análisis consciente" (Hasbún, 2015, p. 49).

\section{OBJETIVOS}

La pregunta que rige el camino de investigación es: ¿el framing que ofrecen los medios sobre un tema de interés público es distinto si son tradicionales o si son nativos digitales?

Para responder a este cuestionamiento, se establecen los siguientes objetivos: (O1) Detectar los criterios de noticiabilidad con los que aborda el tema cada medio; $(\mathrm{O} 2)$ Identificar actores políticos presentes en las piezas informativas denominadas como fuentes informativas; (O3) Codificar los valores culturales a los que apelan las fuentes informativas que los medios deciden publicar como interlocutores autorizados para tratar el tema; (O4) Interpretar el encuadre que realiza cada medio sobre el tema. 
Aproximación al Framing en medios tradicionales y en nativos digitales. El caso del impuesto a las hipotecas en España

\section{METODOLOGÍA}

El análisis de contenido es una forma de abordar los sentidos manifiestos y ocultos de los textos comunicativos a partir de la sistematización y codificación de los datos que esos textos aportan (Krippendorff, 1997; Neuendorf, 2002; Wimmer y Dominick, 1996). Desde este método se establecen categorías y - en el caso de que sea necesariosubcategorías que se codifican por cada unidad de análisis.

A partir de una metodología de análisis de contenido mixta (Johnson y Onwuegbuzie, 2004; Piñuel, 2002), los datos recolectados se codifican e interpretan para generar una aproximación a las resonancias culturales y mediáticas (Sádaba et al., 2008) que estos actores defienden, y poder conocer, desde una perspectiva inductiva, el tipo de encuadre predominante que ofrecen los medios analizados.

Desde un enfoque marcado por el framing (Entman, 1993; Price, Tewksbury y Powers, 1997; Scheufele, 1999; Reese, 2001; Sádaba et al., 2008) se analiza el encuadre en medios de referencia de España para conocer las posibles diferencias entre medios nativos y no nativos digitales.

En el análisis, las fuentes significan un elemento clave, en se constituyen como indicadores de la presencia e influencia de actores políticos relevantes en el mundo social y político (Harris y McGrath, 2012; Klüver, 2012 y Baldi, 1990).

Un informe anual de Reuters Institute de la Universidad de Oxford (2018) concluyó que en España los medios con más audiencia son El País, El Mundo coincidente con el Estudio General de Medios 2018- y en el caso de los nativos digitales, ElConfidencial.com y Eldiario.es.

Tabla 1. Rasgos más significativos de cada medio

\begin{tabular}{|c|c|c|c|c|}
\hline Medio & $\begin{array}{l}\text { Edición } \\
\text { impresa }\end{array}$ & Edición digital & Director/a & Propietario \\
\hline El país & desde 1976 & desde 1996 & $\begin{array}{l}\text { Soledad } \\
\text { Gallego-Díaz }\end{array}$ & $\begin{array}{l}\text { El Grupo Prisa } \\
\text { pertenece en un } \\
40 \% \text { a Liberty } \\
\text { Adcquisitions } \\
\text { LLC, integrada } \\
\text { por entidades } \\
\text { financieras } \\
\text { como Goldman } \\
\text { Sachs, Credit } \\
\text { Suisse } \\
\text { Deutsche Bank, } \\
\text { entre otros. Otro } \\
20 \% \text { es } \\
\text { propiedad de la } \\
\text { unión del Banco } \\
\text { Santander, La } \\
\text { Caixa y HSBC. }\end{array}$ \\
\hline
\end{tabular}


Quintana Pujalte, L.

Aproximación al Framing en medios tradicionales y en nativos digitales. El caso del impuesto a las hipotecas en España

\begin{tabular}{|c|c|c|c|c|}
\hline El Mundo & 1986 & 1995 & $\begin{array}{ll}\text { Pedro } & \text { J. } \\
\text { Ramírez } & \end{array}$ & $\begin{array}{l}\text { Unidad } \\
\text { Editorial S.A. } \\
\text { que pertenece } \\
\text { en un } 96 \% \text { a } \\
\text { RCS } \\
\text { Mediagroup, } \\
\text { participado por } \\
\text { empresas como } \\
\text { el banco italiano } \\
\text { Mediobanca o } \\
\text { Fiat, entre otros. }\end{array}$ \\
\hline Elconfidencial.com & - & 2001 & Nacho Cordero & $\begin{array}{l}\text { Titania } \\
\text { Compañía } \\
\text { Editorial SL y } \\
\text { sus empresas } \\
\text { subsidiarias } \\
\text { Vanitatis SL y } \\
\text { Titania Eventos } \\
\text { SL. }\end{array}$ \\
\hline Eldiario.es & - & 2012 & Ignacio Escolar & $\begin{array}{l}\text { Diario de Prensa } \\
\text { Digital S.L. Más } \\
\text { del } 70 \% \text { de esta } \\
\text { empresa está en } \\
\text { manos de } \\
\text { personas que } \\
\text { trabajan } \\
\text { diariamente en } \\
\text { la redacción. } \\
\end{array}$ \\
\hline
\end{tabular}

Fuente: Elaboración propia

En estos medios considerados de referencia para la audiencia española se buscaron piezas informativas en las que se realizó el tratamiento sobre el impuesto a las hipotecas en España, entre octubre y noviembre de 2018.

La herramienta MyNews fue el motor de búsqueda de las piezas informativas que trataron el tema entre el 16 de octubre y el 9 de noviembre de 2018. Los términos para identificar estas piezas fueron \#hipoteca \#Impuesto \#ActosJurídicosDocumentados, y el filtro por cada medio y periodo de tiempo. Luego de la lectura individual de cada pieza que ofreció el motor de búsqueda, el universo se conformó finalmente por 389 piezas informativas, con la siguiente distribución: El Mundo (n=55), El País $(\mathrm{n}=50)$, El Confidencial $(\mathrm{n}=191)$ y Eldiario.es $(\mathrm{n}=93)$.

En la plantilla, cada noticia, crónica, artículo de opinión y editorial que conforman el universo es una unidad de análisis, identificada con números ordinales. Para conocer las resonancias mediáticas se realizó el foco en el titular de las piezas informativas, entendiendo que es allí donde el medio destaca lo que considera más relevante sobre los acontecimientos (Pan y Kosicki, 1993). Del universo emergieron tres criterios de noticiabilidad con los que se trató el tema. 
Quintana Pujalte, L.

Aproximación al Framing en medios tradicionales y en nativos digitales. El caso del impuesto a las hipotecas en España

En cada pieza informativa, se identifica el criterio de noticiabilidad, el género periodístico al que pertenece la unidad de análisis y el origen de la información (si viene de agencia de noticias o es información del medio). Además, se codifican las categorías de fuentes informativas y los valores culturales que defienden. Cada categoría se dividió en subcategorías que emergieron del análisis.

En la plantilla se observa tanto la frecuencia de aparición de criterios de noticiabilidad y de las fuentes de información con mayor presencia en el universo de análisis, así como también valores culturales a los que éstas apelan, siendo estos últimos datos que los que ofrecen una aproximación más cualitativa al contenido publicado. La interpretación transversal que ofrece sirve de herramienta para interpretar el encuadre que se ofrece desde los medios seleccionados.

Tabla 2. Categorías y subcategorías de análisis

\begin{tabular}{|c|c|c|}
\hline Categorías & \multicolumn{2}{|l|}{ Subcategorías } \\
\hline Criterios de noticiabilidad & \multicolumn{2}{|l|}{$\begin{array}{l}\text { 1. Conflicto } \\
\text { 2. Consecuencia } \\
\text { 3. Dinero }\end{array}$} \\
\hline Fuentes & \multicolumn{2}{|c|}{$\begin{array}{l}\text { IV. Ciudadanos afectados } \\
\text { V. Privadas (representantes de la Banca o } \\
\text { sociedades que representan intereses privados) } \\
\text { VI. Informes, índices y estadísticas. Se incluyen } \\
\text { aquí documentos del poder legislativo } \\
\text { VII. Especializadas (catedráticos y especialistas en } \\
\text { temas jurídicos no vinculados a los poderes del } \\
\text { Estado; despacho de abogados, consultores y } \\
\text { economistas, agencias de calificación crediticia) } \\
\text { VIII. Organismos internacionales } \\
\text { IX. Fuentes no identificadas } \\
\text { X. Sindicales }\end{array}$} \\
\hline Valores culturales & A. Justicia & $\begin{array}{l}\text { Se consideró que las } \\
\text { fuentes hacían } \\
\text { referencia a este valor } \\
\text { cuando manifestaban } \\
\text { la importancia de que } \\
\text { se realice lo que es } \\
\text { justo apoyándose en } \\
\text { una idea colectiva de } \\
\text { la Justicia y de las }\end{array}$ \\
\hline
\end{tabular}


Quintana Pujalte, L.

Aproximación al Framing en medios tradicionales y en nativos digitales. El caso del impuesto a las hipotecas en España

\begin{tabular}{|c|c|c|}
\hline & & $\begin{array}{l}\text { normas sociales que la } \\
\text { aseguran. }\end{array}$ \\
\hline & Responsabili & \begin{tabular}{lr}
\multicolumn{3}{l}{ Se consideró que las } \\
fuentes apuntaban a \\
este valor cuando \\
hacían referencia a \\
que ciertos actores \\
deben & ser \\
responsables de & sus \\
decisiones; o & cuando \\
consideraban & que \\
cierta acción & era \\
producto & del \\
compromiso & $\mathrm{u}$ \\
obligación. &
\end{tabular} \\
\hline & $\begin{array}{l}\text { C. Estado } \\
\text { Responsable }\end{array}$ & $\begin{array}{l}\text { Se consideró que las } \\
\text { fuentes apelaban a } \\
\text { este valor cuando } \\
\text { ponían al Estado y a } \\
\text { sus funciones como } \\
\text { actor fundamental } \\
\text { para resolver el } \\
\text { conflicto. }\end{array}$ \\
\hline & Defensa de derechos & $\begin{array}{l}\text { Se consideró que se } \\
\text { apelaba a este valor } \\
\text { cuando las fuentes } \\
\text { invitaban } \\
\text { manifestarse o a } \\
\text { revelarse contra algo } \\
\text { establecido por otros }\end{array}$ \\
\hline & Valores del mercado & 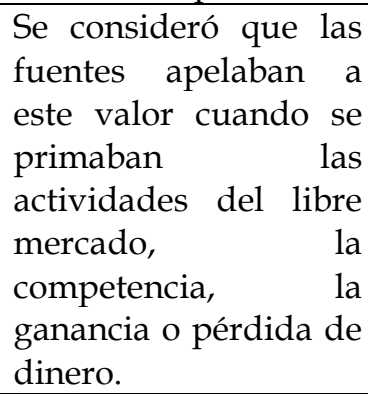 \\
\hline
\end{tabular}

Fuente: Elaboración propia

\section{RESULTADOS}

Para responder al primer objetivo se codificaron las 389 piezas informativas con los criterios de noticiabilidad que proponían para el abordaje del tema. En el gráfico 1 se pueden apreciar los criterios con los que los medios tradicionales encuadraron el tema: 
Quintana Pujalte, L.

Aproximación al Framing en medios tradicionales y en nativos digitales. El caso del impuesto a las hipotecas en España

El Mundo $\quad$ El País

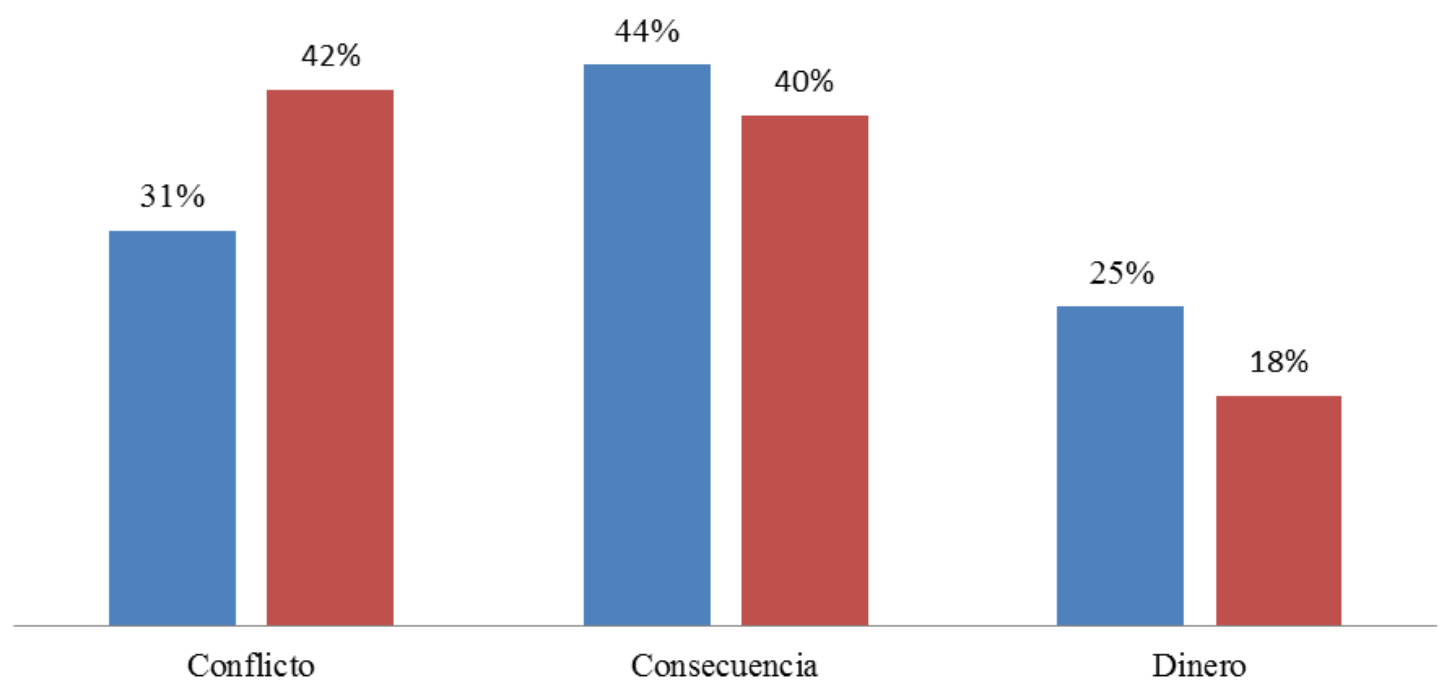

Gráfico 1. Criterios de noticiabilidad en medios tradicionales

Fuente: elaboración propia

La cobertura predominante desde el diario El Mundo fue desde la consecuencia, con una presencia del $44 \%$. Es decir que al realizar el tratamiento del tema el medio enfatizó en el titular las causas y/o los potenciales efectos del mismo. Las nociones de conflicto y la referencia al dinero ocupan el segundo (31\%) y tercer lugar (25\%), respectivamente.

Por su parte, el diario El País puso énfasis en la faceta conflictiva del tema en el $42 \%$ de las veces, ofreciendo titulares con sintagmas como "caos", "división", "confusión". En segunda instancia, el criterio de noticiabilidad que señala las consecuencias del tema en cuestión fue significativo en los titulares del medio, con el $40 \%$ de la presencia. Muy por detrás de estos dos, se presenta el criterio vinculado al dinero $(18 \%)$.

La cobertura que ofrece El Mundo en comparación con la de El País es que la primera hace énfasis en las consecuencias que tiene el acontecimiento noticioso; esto es, se preocupa en construir un camino informativo para que el público pueda comprender de modo más profundo las implicancias de cada momento vinculado al tema: la publicación del fallo y el cambio de doctrina, la caída de los bancos que cotizan en Bolsa, la reconsideración del fallo a partir del Pleno, el regreso a la anterior doctrina en la que era el cliente quien pagaba el impuesto, y luego la publicación del Real Decreto ley para revertir la decisión a que sea la Banca quien deba afrontar el costo del impuesto.

El País, sin embargo, ofrece una cobertura balanceada entre el enfoque que destaca el tema como conflictivo y en marcar también sus consecuencias. Para este medio 
Quintana Pujalte, L.

Aproximación al Framing en medios tradicionales y en nativos digitales. El caso del impuesto a las hipotecas en España

aunque el criterio del dinero es parte de la construcción del encuadre, la presencia es significativamente más baja que los otros dos criterios.

En cuanto a los nativos digitales es el medio ElConfidencial.com el que lidera la cobertura en cuanto a cantidad de publicaciones sobre el tema. En el gráfico 2 se observa que enfatizó el tratamiento a partir del criterio vinculado al dinero $(42 \%$ de las piezas informativas). En segundo lugar, aparecen titulares que resaltan el tema desde la faceta del conflicto (36\%) y en último lugar, desde la consecuencia (22\%).

El criterio a partir del cual este medio abordó la cuestión se muestra claramente diferenciado del modo en que lo hicieron los medios tradicionales, más enfocados en explicar causas y consecuencias, o establecer las bases conflictivas del tema.

Los resultados correspondientes al análisis del tratamiento de Eldiario.es, sin embargo, indican que se enfoca en destacar las características vinculadas al conflicto $(51 \%)$, luego al dinero (32\%) y muy por detrás, al de las consecuencias (17\%). Entre ambos medios, el criterio de noticiabilidad vinculado al dinero tiene un alto nivel de presencia en las piezas informativas analizadas.
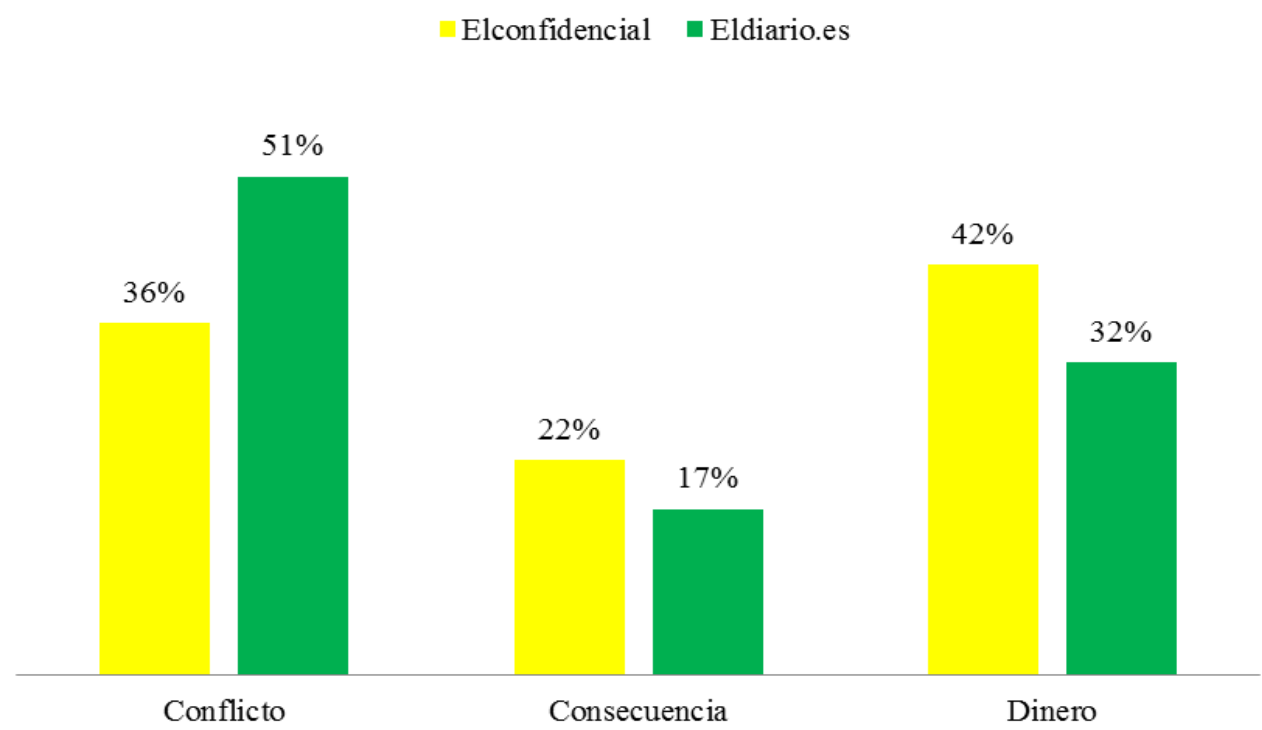

Gráfico 2. Criterios de noticiabilidad en medios nativos digitales

Fuente: elaboración propia

La comparativa entre los criterios de noticiabilidad para la cobertura periodística entre medios tradicionales y nativos digitales permite observar diferencias significativas en el tratamiento en cuanto al criterio vinculado al dinero. Este se enfatiza en gran medida en medios nativos digitales en el $83 \%$ de las piezas informativas frente al $17 \%$ de los medios tradicionales. En cuanto a los otros dos criterios, de modo comparativo, el criterio del conflicto tiene una presencia más alta en medios nativos digitales que en medios tradicionales $75 \%$ de los primeros frente al $25 \%$ de los segundos. El foco puesto en las consecuencias, los medios no presentan grandes diferencias, $57 \%$ en nativos digitales y $43 \%$ en los tradicionales. 


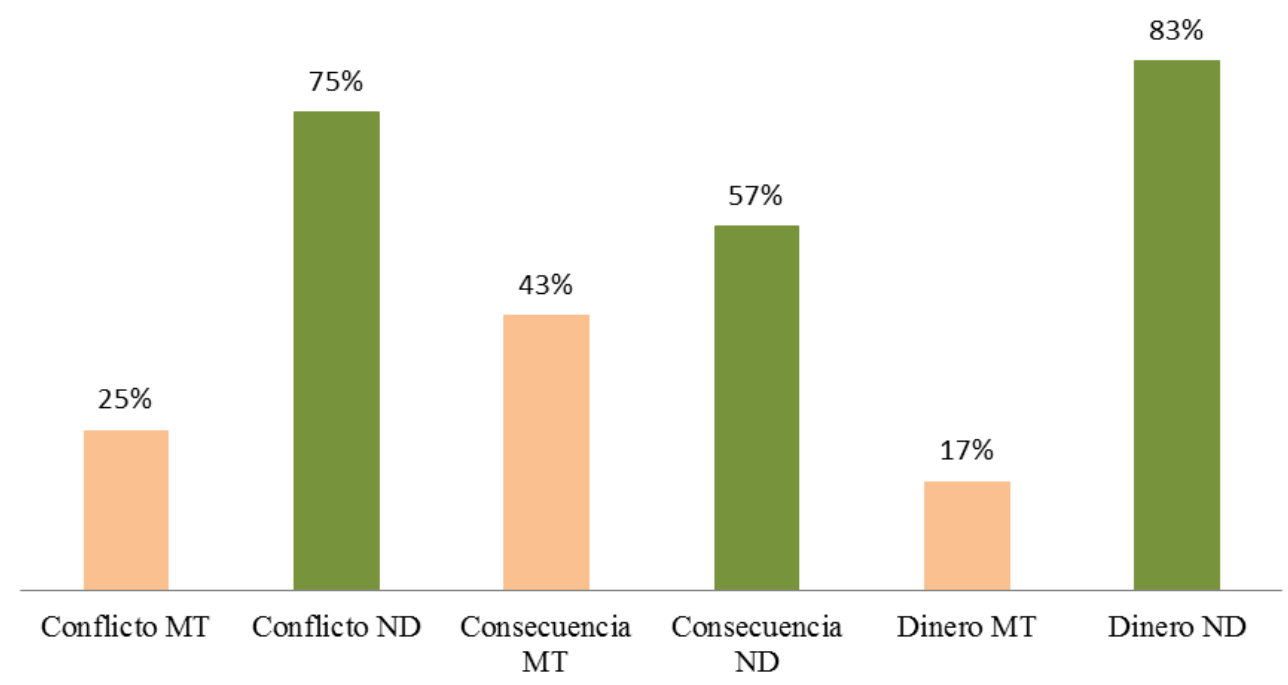

Gráfico 3. Comparativa entre criterios de noticiabilidad medios tradicionales (MT) y nativos digitales (ND)

Fuente: elaboración propia

El encuadre que proponen medios tradicionales y nativos digitales desde los géneros periodísticos es otro elemento que permite interpretar el énfasis que realizan sobre un tema de carácter público. Como se puede observar en el gráfico 4, el género de la noticia fue predominante en el tratamiento de los medios nativos digitales, seguido por la crónica. En el caso de los medios tradicionales, la crónica ocupa el primer lugar, seguido por la noticia.

La noticia ofrece un tratamiento menos profundo de las temáticas y se vincula a un formato menos comprometido que la crónica. En esta última, el desarrollo del acontecimiento es pormenorizado por tener que responder a las causas e impacto del tema tratado.

Un dato interesante es el referente al tratamiento en artículos de opinión, el cual se muestra con un alto grado de similitud entre medios tradicionales y en nativos digitales. El editorial sólo se ha podido observar en medios tradicionales. 
Quintana Pujalte, L.

Aproximación al Framing en medios tradicionales y en nativos digitales. El caso del impuesto a las hipotecas en España

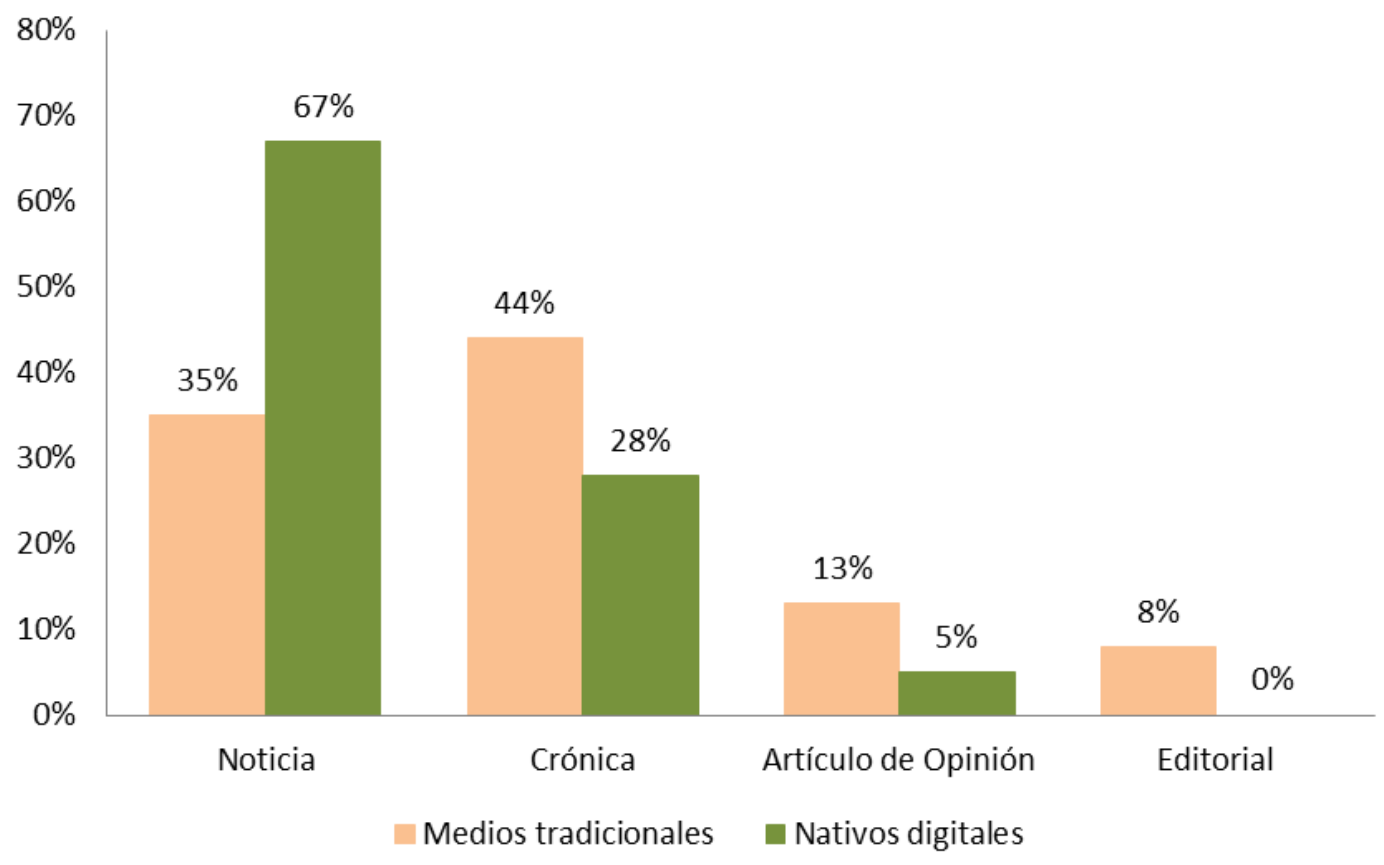

Gráfico 4. Géneros periodísticos para el tratamiento del tema en medios tradicionales y en nativos digitales

Fuente: Elaboración propia

El análisis toma como un aspecto relevante el tratamiento que realizan los medios a partir de las fuentes de información. Estas representan actores políticos de relevancia que al tener presencia mediática pueden moldear la opinión pública gracias al "control del ingreso de las pretensiones en el sistema político" (Castillo, et. al, 2017, p. 786).

En el gráfico 5 se puede observar que en el caso de los medios tradicionales El Mundo y El País comparten entre ambos la presencia de fuentes de carácter privado para la construcción de sus piezas informativas. Por otro lado, para El Mundo la palabra de las fuentes político-institucionales y especializadas tiene un gran valor periodístico, a diferencia de El País, medio que ofrece coberturas con una alta presencia de fuentes sin identificar. La utilización de los discursos de los organismos internacionales en ambos medios es muy baja, y es inexistente la presencia de ciudadanos afectados como fuente. 
Quintana Pujalte, L.

Aproximación al Framing en medios tradicionales y en nativos digitales. El caso del impuesto a las hipotecas en España

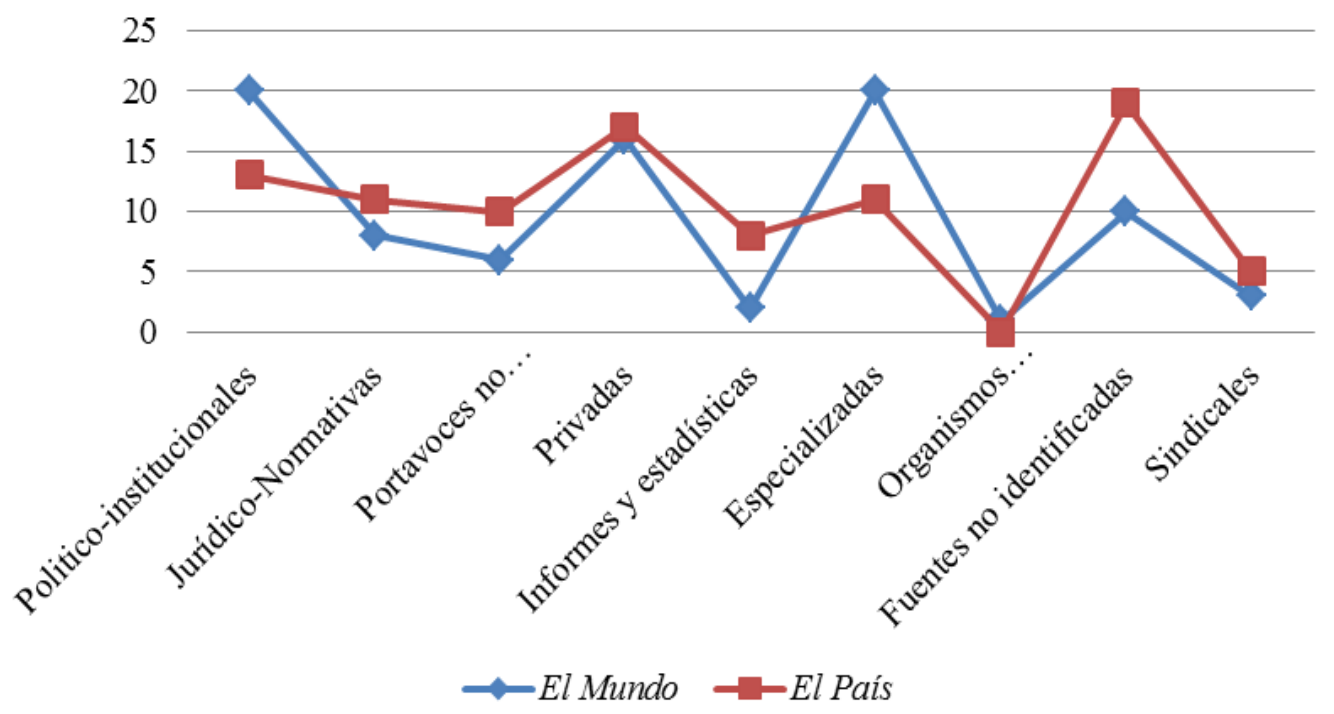

Gráfico 5. Relación de uso de fuentes informativas en medios tradicionales

Fuente: elaboración propia

Los datos que se recogen del universo de piezas informativas de medios nativos digitales muestran tendencias bien diferenciadas entre ambos, y entre estos y los tradicionales. Se puede observar en el Gráfico 6 que en el caso de ElConfidencial.com el medio destaca la presencia de fuentes privadas, especializadas y de informes y estadísticas para encuadrar el tema. Por su parte, Eldiario.es ofrece un tratamiento a partir de fuentes que tienen una presencia homogénea en las piezas analizadas. Estos datos indican que el medio no se basa en actores políticos específicos que propongan una lectura hegemónica de los acontecimientos.

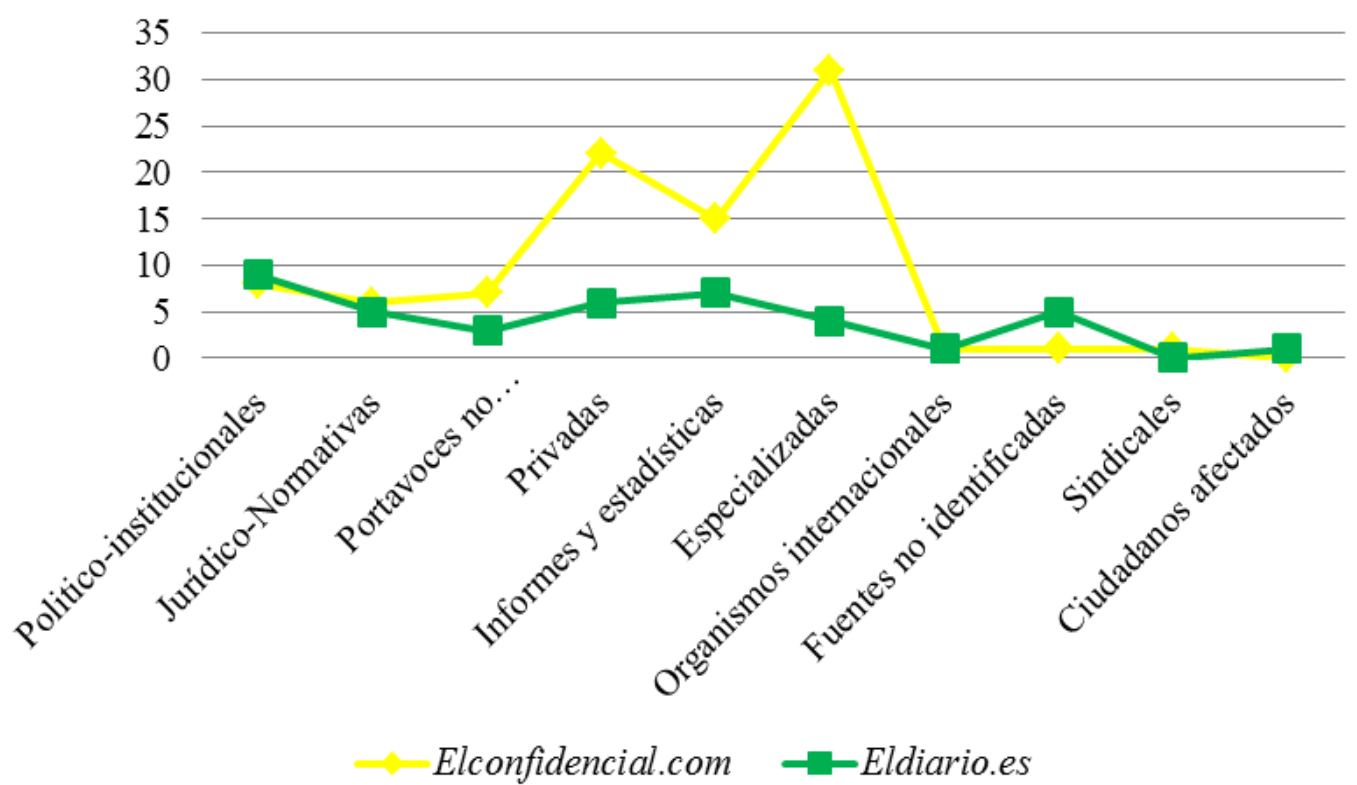

Gráfico 6. Relación de uso de fuentes en nativos digitales

Fuente: elaboración propia 
El análisis comparativo del tratamiento desde las fuentes que realizan medios tradicionales y nativos digitales en el total de cada universo analizado, arroja datos interesantes sobre el uso frecuente de las fuentes no identificas por parte de los medios tradicionales (16\%) frente a los nativos digitales quienes apelan a este recurso en un $4 \%$ de las veces. Otra diferencia significativa es en la apelación a fuentes especializadas, en el $26 \%$ de las piezas informativas en el caso de los nativos digitales y en el $17 \%$ en los medios tradicionales. El uso de informes y estadísticas es más frecuente en los nativos digitales ( $17 \%$ del total de las piezas informativas) que en los medios tradicionales $(6 \%$ del total analizados correspondientes a este tipo de medios).

Las fuentes privadas ostentan una alta presencia en ambos tipos de medios, en el $21 \%$ de las piezas correspondientes a medios nativos digitales y en el $19 \%$ de las piezas de medios tradicionales. La presencia de fuentes político-institucionales en medios tradicionales es de $18 \%$, mientras que en los nativos digitales la presencia es más baja $(13 \%)$.

En cuanto a las fuentes jurídico-normativas, los portavoces no gubernamentales, los organismos internacionales, las fuentes sindicales y los ciudadanos afectados, se observa que aparecen una frecuencia similar tanto en medios tradicionales como en nativos digitales.

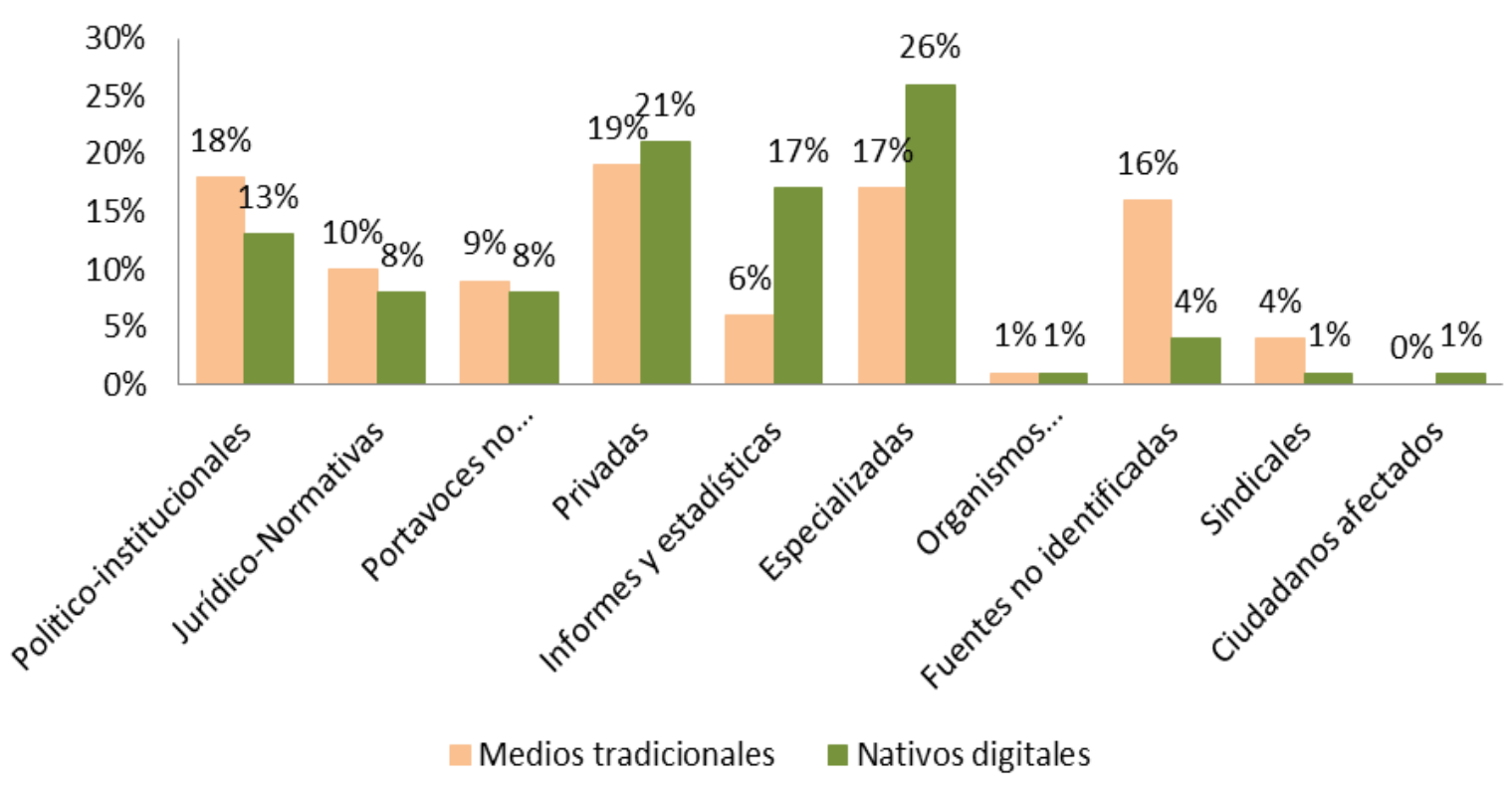

Gráfico 7. Comparativa de uso de fuentes en medios tradicionales y nativos digitales Fuente: elaboración propia

El análisis se enfoca luego en conocer los valores a los que apelan los actores políticos que tienen presencia en el tratamiento mediático que realiza cada medio. Luego de la codificación de los valores culturales que defiende cada una de las 
Quintana Pujalte, L.

Aproximación al Framing en medios tradicionales y en nativos digitales. El caso del impuesto a las hipotecas en España

fuentes informativas presentes en el universo de análisis del diario El Mundo se puede observar que existe una alta apelación a los valores de mercado desde distintas fuentes, no sólo las de origen privado.

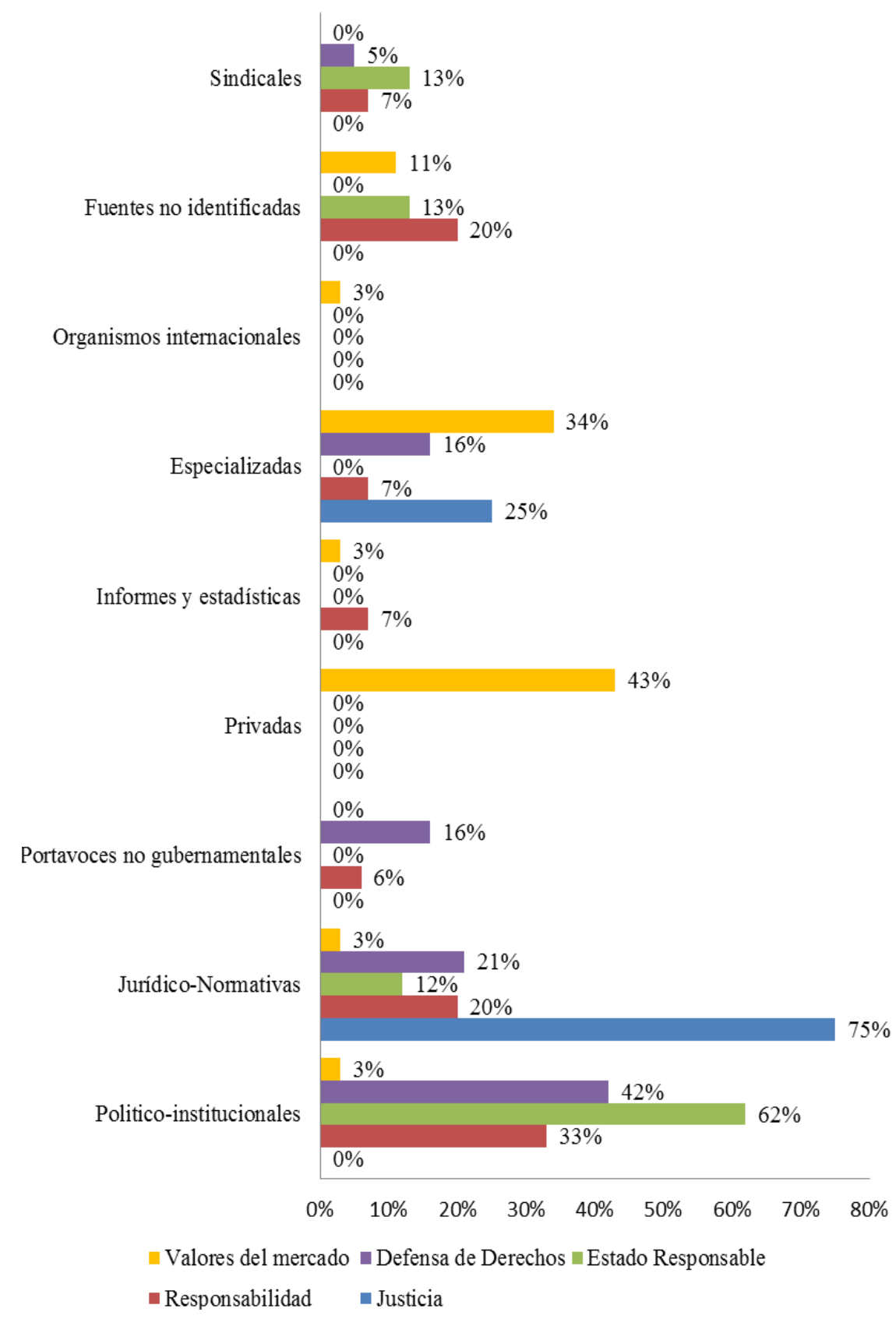

Gráfico 8. Valores culturales a los que apelan las fuentes informativas. Diario El Mundo

Fuente: elaboración propia

En el caso de los valores a los que apelan los actores políticos presentes en el tratamiento de El País, el medio enfatiza a través de ellos los valores del mercado, la noción del Estado responsable y la defensa de derechos. 
Quintana Pujalte, L.

Aproximación al Framing en medios tradicionales y en nativos digitales. El caso del impuesto a las hipotecas en España

Un dato llamativo es que detrás de los portavoces no gubernamentales, sean las fuentes no identificadas las que apelan con mayor frecuencia a la defensa de derechos.

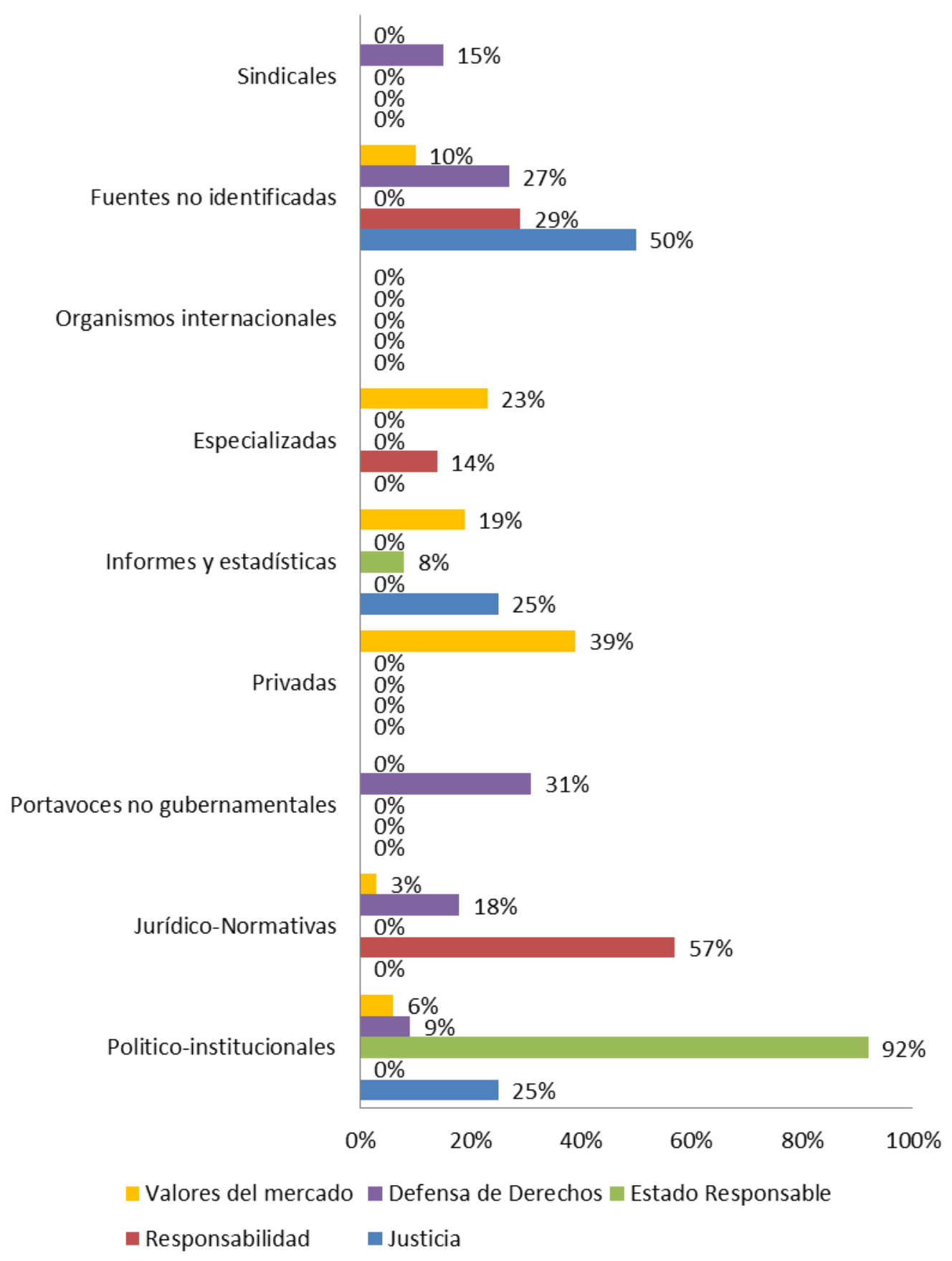

Gráfico 9. Valores culturales a los que apelan las fuentes informativas. Diario El País Fuente: elaboración propia

La codificación de los valores a los que hacen referencia las fuentes informativas en ElConfidencial.com muestra que son las fuentes no identificadas las que en mayor medida apelan al valor de la responsabilidad. Por su parte, el valor de la responsabilidad del Estado ante la situación está polarizado por las fuentes político- 
Quintana Pujalte, L.

Aproximación al Framing en medios tradicionales y en nativos digitales. El caso del impuesto a las hipotecas en España

institucionales y las fuentes no identificadas. La justicia es un valor que, a diferencia de los medios tradicionales, se distribuye en tres fuentes distintas que apelan en gran medida a ésta (las jurídico-normativas, las fuentes no identificadas y las especializadas). Nuevamente, se puede apreciar que la presencia de los valores del mercado se encuentra representada en un grado mayor en las fuentes privadas y en las especializadas, seguidas de los informes y estadísticas.

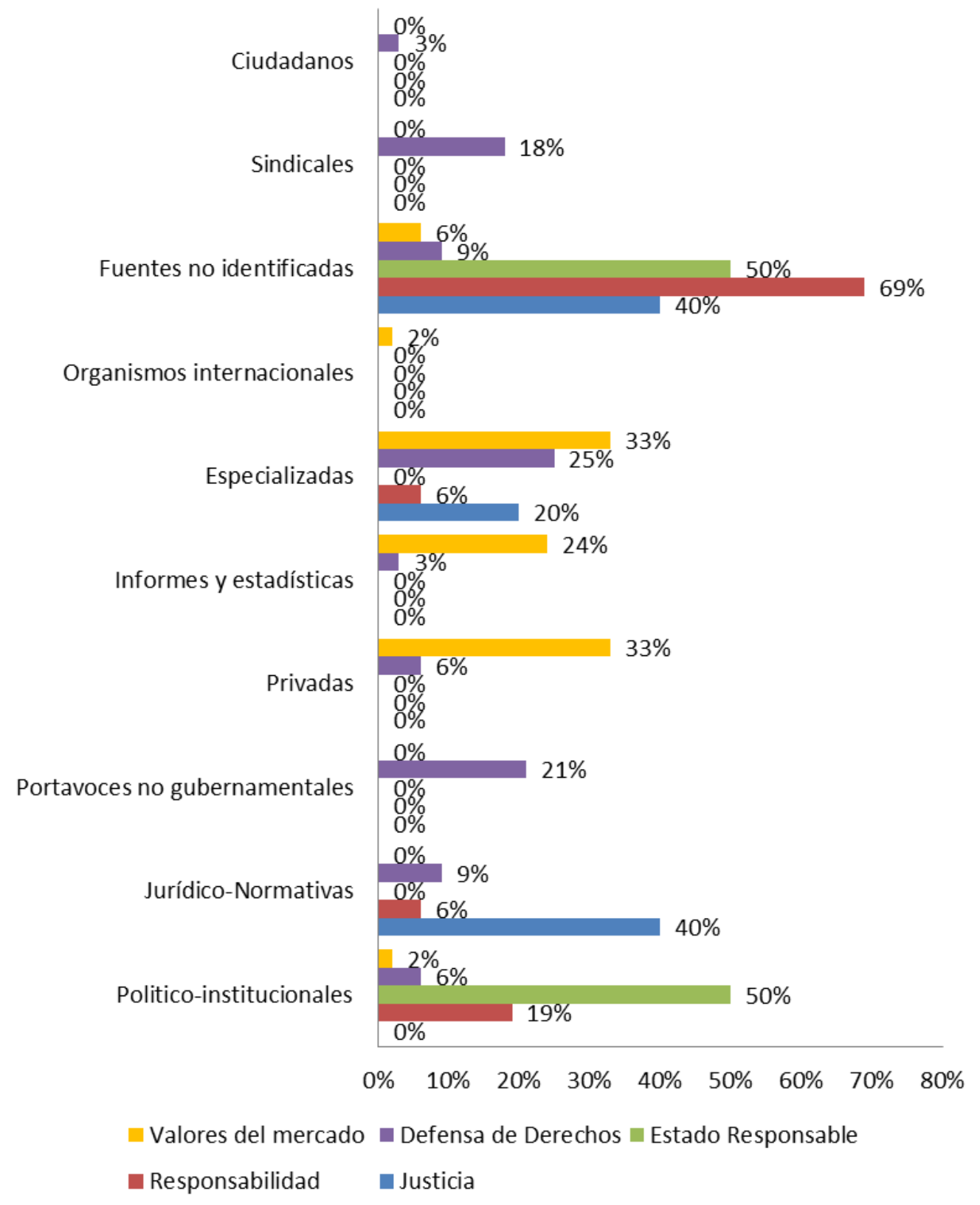

Gráfico 10. Valores culturales a los que apelan las fuentes informativas, Elconfidencial.com

Fuente: elaboración propia

Esta presencia de fuentes que hacen referencia a la importancia de los valores del mercado se repite en Eldiario.es. Esta cuestión aparece en el tratamiento mediático 
Quintana Pujalte, L.

Aproximación al Framing en medios tradicionales y en nativos digitales. El caso del impuesto a las hipotecas en España

que se realiza desde seis de las diez fuentes identificadas, entre ellas se destaca la apelación a este valor por parte de las fuentes privadas, los informes y estadísticas y de modo llamativo, desde las fuentes no identificadas que aparecen en las piezas informativas. Mientras que los valores de la responsabilidad y del Estado responsable se polarizan en fuentes institucionalizadas como las políticoinstitucionales y las jurídico-normativas.

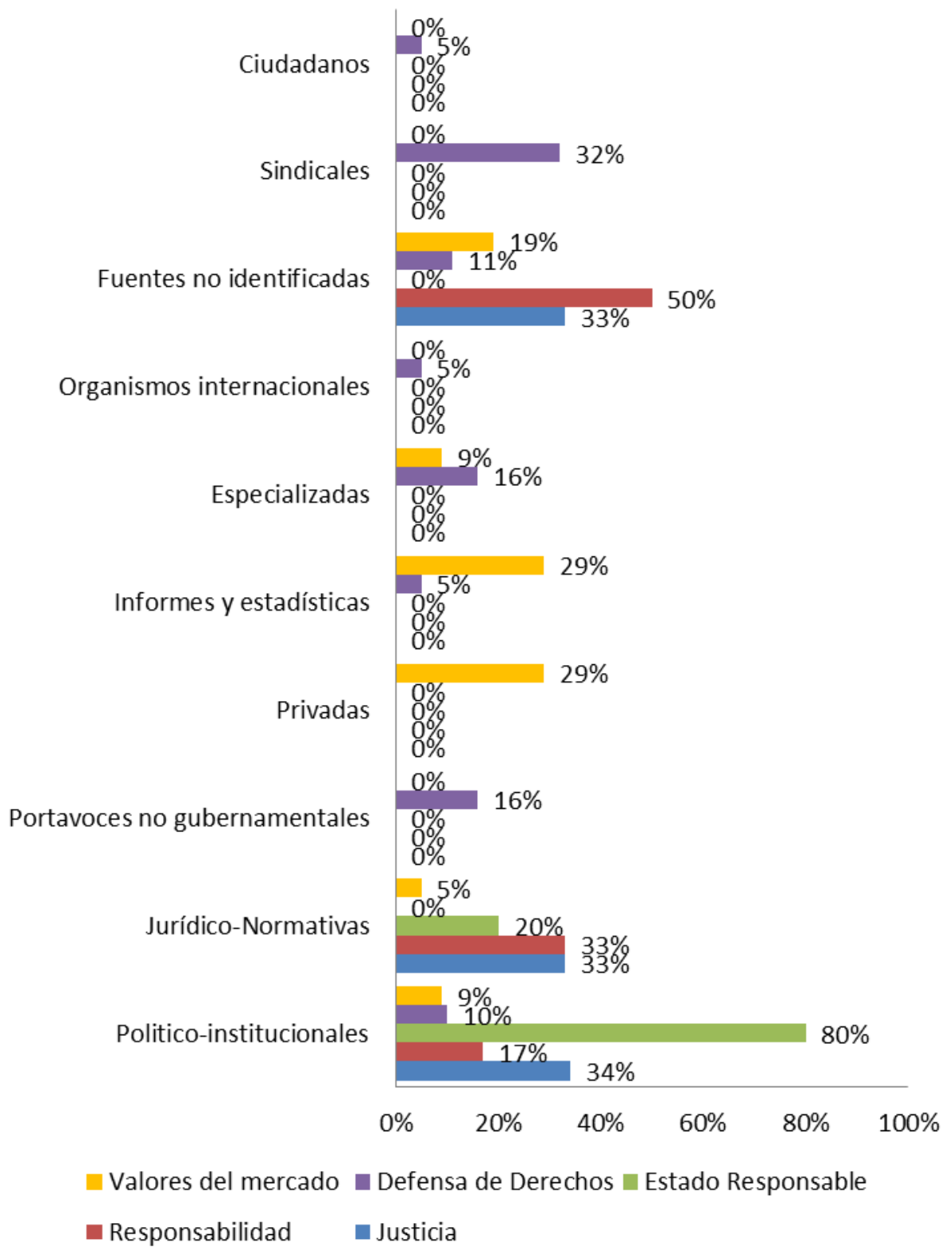

Gráfico 11. Valores culturales a los que apelan las fuentes informativas. Eldiario.es Fuente: elaboración propia

La codificación total de estos valores culturales en medios tradicionales y en nativos digitales del gráfico 12 indica que existen similitudes en la presencia de estos en el total de las piezas analizadas. Medios tradicionales y nativos digitales enfatizan desde distintas fuentes informativas aspectos vinculados a libre mercado, subas y 
Quintana Pujalte, L.

Aproximación al Framing en medios tradicionales y en nativos digitales. El caso del impuesto a las hipotecas en España

bajas en la Bolsa, la competencia entre actores económicos, efectos positivos o negativos de oferta y demanda, entre otros.

Se puede apreciar el interés por parte de los medios tradicionales en enfatizar la defensa de derechos a partir de distintas fuentes presentes en las piezas publicadas.

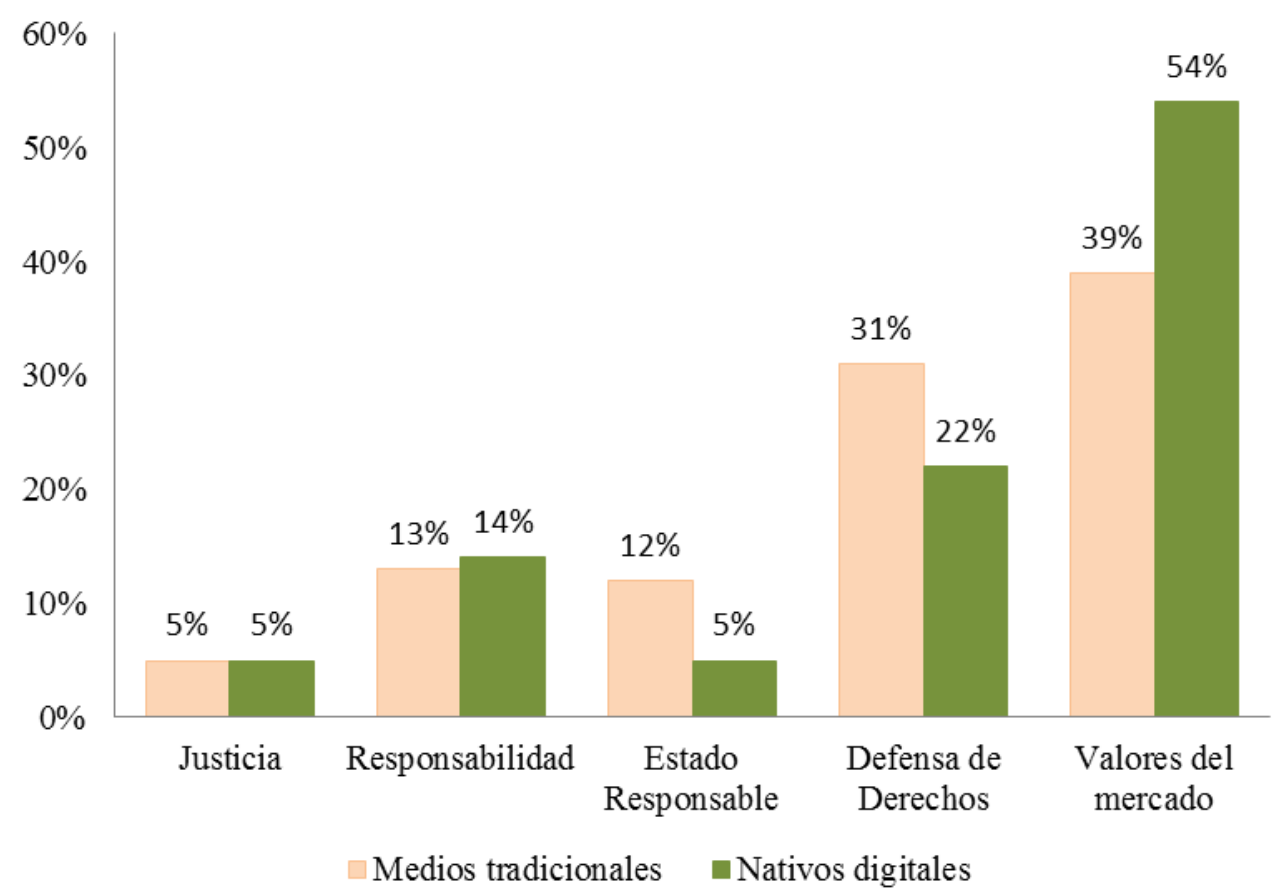

Gráfico 12. Comparativa de valores culturales presentes en medios tradicionales y nativos digitales

Fuente: elaboración propia

El análisis partió de cada una de las piezas informativas que conformaron el universo, de dónde emergieron las categorías de análisis codificadas. Estos datos procesados permiten interpretar los encuadres que cada medio ofreció para la comunicación pública de este acontecimiento.

En el caso de los medios tradicionales encuadraron el tema como un conflicto político-institucional con implicancias económicas y políticas. Este frame se construye a partir de la preeminencia del tipo de fuentes y los valores a los que apelan.

En cuanto a los nativos digitales, presentan el tema a partir de un encuadre que ofrece una interpretación fundamentalmente economicista, con especial énfasis en las ganancias o pérdidas de dinero, tanto de la Banca como de otros actores.

\section{DISCUSIÓN}

En coincidencia con hallazgos de otros estudios (Tirado-Pascual, 2016; SánchezCastillo, et. al., 2016) el grado de exposición de los actores políticos varía cuando el 
Quintana Pujalte, L.

Aproximación al Framing en medios tradicionales y en nativos digitales. El caso del impuesto a las hipotecas en España

encuadre se realiza desde medios tradicionales de cuando se realiza desde medios nativos digitales. Cuando los primeros muestran aún una fuerte vinculación a los actores políticos institucionalizados, los segundos proponen la presencia de una variedad de fuentes, entre las que priman informes, estadísticas y fuentes especializadas.

Es llamativo el alto índice de fuentes no identificadas que aparecen en las coberturas de los medios tradicionales. Esto podría ser un tema de estudio en profundidad que busque, por un lado, determinar si esta práctica se relaciona con una deficiencia en la labor periodística (Casero-Ripollés y López-Rabadán, 2013) o, por otro lado, con la legitimidad autopercibida por el medio que significaría no estar obligado a citar sus fuentes.

Frente a este recurso utilizado por los medios tradicionales, los nativos digitales se apoyan con mayor frecuencia en fuentes especializadas e informes y estadísticas. En este aspecto, su lógica de producción periodística se sustenta en dar voz con mayor intensidad a otro tipo de fuentes que diferencian el modo de

El discurso de la Banca es hegemónico en ambos encuadrar los acontecimientos y le otorga cierto grado de independencia con respecto a los actores institucionales (Tirado-Pascual, 2016).

\section{CONCLUSIÓN}

Entre los resultados más relevantes está la identificación de actores políticos de distinta relevancia con presencia mediática, entre los que se destaca la Banca, fuentes especializadas y representantes de partidos políticos y del poder ejecutivo. Las asociaciones de defensa al consumidor y los sindicatos tienen una presencia baja en el total de las piezas analizadas. Tal como se ha identificado en otros estudios (Hasbun, 2015) los ciudadanos afectados tienen una presencia muy baja en los encuadres de los medios nativos digitales y están ausentes en el tratamiento de los medios tradicionales. El resultado es llamativo ya que la ausencia de los principales discurso damnificados por el impuesto de las hipotecas, invisibiliza este colectivo en el de los medios tradicionales.

El discurso de la Banca es hegemónico en espacios mediáticos, y la defensa de los valores de mercado tiene una presencia contundente. Esta alta presencia de la defensa de los intereses de este actor en los medios construye una opinión pública que conoce de modo preferencial los intereses de estos grupos privados. 
Quintana Pujalte, L.

Aproximación al Framing en medios tradicionales y en nativos digitales. El caso del impuesto a las hipotecas en España

\section{REFERENCIAS}

Andersen, S., \& Eliasen, K. (1991). European Community Lobbying. European Journal of Political Research, 20(2), 173-187.

Asociación para la Investigación de Medios de Comunicación (2018). Resumen General de Medios. Recuperado de https://www.aimc.es/a1mcc0nt3nt/uploads/2018/06/resumegm218.pdf

Benkler, Y. (2015). La riqueza de las redes: Cómo la producción social transforma los mercados y la libertad. España, Barcelona: Icaria.

Berrocal, S., Redondo, M. y Torres, L. (2015). La crisis como espectáculo, el info entretenimiento en las noticias sobre el rescate bancario en la prensa de referencia. Communication \& Society, 28(4), 1-16

Casero-Ripollés, A. y López-Rabadán, P. (2013). La gestión de fuentes informativas como criterio de calidad profesional. En (Gómez-Mompart, J. L., Gutiérrez, J. F., Palau, D. 2013), La calidad periodística. Teorías, investigaciones y sugerencias profesionales. Barcelona: Aldea Global.

Castillo-Esparcia, A. (2011): Lobby y Comunicación. Sevilla, España: Editorial Comunicación Social.

Castillo-Esparcia, A., Smolak-Lozano, E. y Fernández-Souto, A. (2017). Lobby y comunicación en España. Análisis de su presencia en los diarios de referencia. Revista Latina de Comunicación Social (72). 783-802, doi: https://dx.doi.org/ $\underline{10.4185 / R L C S-2017-1192}$

Chadwick, A. (2013) The hybrid media system. Oxford, UK: Oxford Studies in digital politics. doi: https://dx.doi.org//10.1093/acprof:oso/9780199759477.001.0001

De Vreese, C. (2005): News framing: Theory and typology. Information Design Journal 13(1), 51-62.

D'angelo, P. (2002): News Framing as a Multiparadigmatic Research Program: A Response to Entman. Journal of Communication, 52(4), 870-888. doi: http://dx.doi.org/10.1111/j.1460-2466.2002.tb02578.x

Dion, L. (1967). Los grupos y el poder politico en los Estados Unidos. México: Grijalbo.

Easton, D. (1965): Esquema para el análisis político. Buenos Aires, Argentina: Amorrortu Editores. 
Quintana Pujalte, L.

Aproximación al Framing en medios tradicionales y en nativos digitales. El caso del impuesto a las hipotecas en España

Entman, R. (1993): Framing: toward clarification of a fractured paradigm. Journal of Communication, 43(4), 51-58. doi: http://dx.doi.org/10.1111/j.14602466.1993.tb01304.x

Entman, R. (2007): Framing Bias: Media in the Distribution of Power. Journal of Communication, 57(1), 163-173. doi: http://dx.doi.org/10.1111/j.1460$\underline{2466.2006 .00336 . x}$

Gans, H. J. (1980). Deciding what's news. Londres, UK: Constable

Goffman, E. (2006): Frame Analysis. Los marcos de la experiencia. Madrid, España: Centro de Investigaciones Sociológicas.

Hallahan, K. (1999): "Seven models of framing: implications for public relations". Journal of Public Relations Research, 11(3), 205-242. doi: http://dx.doi.org/10.1207/s1532754xjprr1103_02.

Hänggli, R. \& Kriesi, H. (2010): Political Framing Strategies and Their Impact on Media Framing in a Swiss Direct-Democratic Campaign. Political Communication, 27(2), 141-157. doi: http://dx.doi.org/10.1080/10584600903501484

Happer, C. \& Philo, G. (2013). The Role of the Media in the Construction of Public Belief and Social Change. Journal of Social and Political Psychology, 1(1), 321-336. doi: https://dx.doi.org/10.5964/jspp.v1i1.96

Harris, P. \& Mcgrath, C. (2012): Political Marketing and Lobbying: A Neglected Perspective and Research Agenda, Journal of Political Marketing, 11(1-2), 75-94

Hasbún, J. (2015). Análisis de discurso a medios de comunicación digitales en Chile respecto al cambio climático: encuadres para la construcción de las agendas publica y política. Revista Est. de Polticas Publicas, 48-76. doi: http://dx.doi.org/10.5354/0719-6296.2015.38358

Igartúa, J. J., Muñiz, C. y Cheng, L. (2005). La inmigración en la prensa española. Aportaciones empíricas y metodológicas desde la teoría del encuadre noticioso. Revista Migraciones, 17, 143-181

Jenkins, H. (2008) Convergence Culture. La cultura de la convergencia de los medios de comunicación. Barcelona, España: Paidós.

Johnson, R. \& Onwuegbuzie, A. (2004). Mixed methods research: a research paradigm whose time has come. Educational Research, 33(7), 14-26.

Klüver, H. (2012): Informational Lobbying in the European Union: The Effect of Organisational Characteristics. West European Politics, 35(3), 491-510 
Quintana Pujalte, L.

Aproximación al Framing en medios tradicionales y en nativos digitales. El caso del impuesto a las hipotecas en España

Krippendorff, K. (1997). Metodología de análisis de contenido: teoría y práctica. Barcelona, España: Paidós.

McCombs, M. (2004). Setting the agenda: The Mass Media and Public Opinion. Cambridge, UK: Blackwell Polity Press.

Mercado-Sáez, M. T. y Monedero Morales, C. R. (2017). Tratamiento y encuadre de los asuntos energéticos en televisión: análisis de los programas informativos de La Sexta. Communication E Society, 30(4), 115-131

Morozov, E. (2013). To save everything, click here: Technology, solutionism, and the urge to fix problems that don't exist. New York, EEUU: Public Affairs.

Neuman, R., Just, M. y Crigler, A. (1992). Common knowledge. Chicago. EEUU: University of Chicago Press

Neuendorf, K. (2002). The content analysis guidebook. Thousand Oaks (CA): Sage Publications.

Neuman, R., Just, M. y Crigler, A. (1992). Common knowledge. Chicago. EEUU: University of Chicago Press

Pan, Z. y Kosicki, G. (1993). Framing analysis: an aproach to news discourse. Political Communication (10), 55-75

Piñeiro-Naval, V. y Mangana, R. (2019). La presencia del framing en los artículos publicados en revistas hispanoamericanas de comunicación indexadas en Scopus. Palabra Clave 22(1), 117-142. doi: https:/ / dx.doi.org/10.5294/pacla.2019.22.1.6

Piñuel, J. L. (2002). Epistemología, metodología y técnicas de análisis de contenido. Estudios de Sociolingüística, 3(1), 1-42.

Price, V. \& Tewksbury, D. (1997). Switching trains of thought: the impact of news frames on readers'cognitive research. Communication research (24), 481-506.

Reese, S. (2001): A bringing model for media research. En (Reese, S.; Gandy, O. and Grant, A. 2001): Framing Public Life: Perspectives on Media and our Understanding of the Social World. Mahwah, New Jersey, Lawrence Erlbaum Associates, 7-31.

Reuters Institute (2018). Digital News Report, recuperado de http:// media.digitalnewsreport.org/wp-content/uploads/2018/06/digital-newsreport-2018.pdf?x89475 
Quintana Pujalte, L.

Aproximación al Framing en medios tradicionales y en nativos digitales. El caso del impuesto a las hipotecas en España

Rodríguez Pérez, C. (2017). Enfoques de las noticias y legitimidad mediática: estudio exploratorio de la cobertura de la crisis de refugiados en la Unión Europea. Communication \& Society 30(3), 169-184.

Rúas-Araújo, X., Mazaira, A. y Rodriguez-Vazquez, A. I. (2018): Nuevos medios y medios tradicionales en la red. Espacios de opinión e interacción política en la era Trump. Icono 14, 16(1), 86-113. doi: https://dx.doi.org/10.7195/ri14.v16i1.1118

Sádaba, T., Rodríguez-Virgili, J. y La Porte, M. T. (2008). La teoría del framing en la investigación en comunicación. En (Maria José Canel y Mario G. Gurrionero 2008), Estudios de Comunicación Política, ACOP. 15-30

Sadaba, T. y Rodríguez-Virgili, J. (2006). Quién establece los frames: ¿fuentes o medios?. El debate del Estatut en la prensa española, Estudios de periodística XII, Comunicaciones y Ponencias del IX Congreso de la Sociedad Española de Periodística (SEP). Fuentes informativas: sigilo y transparencia, Facultad de Humanidades y Ciencias de la Comunicación. Universidad CEU San Pablo de Madrid, 212-228

Sádaba-Garraza, M. T. (2001). Origen, aplicación y límites de la teoría del encuadre (framing) en comunicación. Comunicación y sociedad, XIV(2), 143-175

Sánchez-Castillo, S., Fenoll, V. y Peris Blanes, A. (2016). Europeísmo y euroescepticismo en los medios digitales españoles. Diferencias de encuadre en la cobertura de las elecciones europeas de 2014. Trípodos, (39), 205-221

Scheufele, D. (1999). Framing as a theory of media effects. Journal of Communication, 49(1), 103-122. doi: http://dx.doi.org/10.1111/j.1460-2466.1999.tb02784.x

Semetko, H. \& Valkenburg, P. (2000). Framing European Politics: a content analysis of press and television news. Journal of Communication, 50(2), 93-109. doi: http://dx.doi.org/10.1111/j.1460-2466.2000.tb02843.x

Tirado-Pascual, N. (2016). Corrupción y fuentes informativas en medios tradicionales y nativos digitales. Miguel Hernandez Communication Journal (7). 257-285.

Vicente-Mariño, M. y López-Rabadán, P. (2009). Resultados de la investigación en comunicación sobre framing: sólido avance internacional y arranque de la especialidad en España. En ZER, Revista de Estudios en Comunicación, 26, 13-34. ISSN: 1137-1102

Warren, C. (1979): Géneros periodísticos informativos. Barcelona, ATE.

Wimmer, R. y Dominick, J. (1996). La investigación científica de los medios de comunicación. Una introducción a sus métodos. Barcelona, España: Bosch 
Quintana Pujalte, L.

Aproximación al Framing en medios tradicionales y en nativos digitales. El caso del impuesto a las hipotecas en España

\section{AUTORA:}

\section{Andrea Leticia Quintana Pujalte}

Magister en Gestión Estratégica e Innovación en la Comunicación; becaria doctoral AUIP por el Doctorado Interuniversitario en Comunicación en la Universidad de Málaga (España). Profesora auxiliar de Opinión Pública en la Universidad Nacional del Nordeste, Argentina (hasta julio 2019)

1.quintanapujallte@uma.es

Orcid: https:// orcid.org/0000-0002-1834-283X

IraLIS: Quintana-Pujalte, Andrea-Leticia (ID: ARCS2200)

Exit ID: https:// www.directorioexit.info/ficha4816

ResearchGate: $\underline{\text { https://www.researchgate.net/profile/Leticia_Quintana_Pujalte }}$ 